\title{
Quantitative MRI for Scoliosis Follow-Up
}

\author{
Périé Delphine \\ Ecole Polytechnique de Montréal, Montréal, \\ Research center, CHU Sainte-Justine, Montréal, \\ Canada
}

\section{Introduction}

Scoliosis deformities progress more during skeletal growth (Bjerkreim et Hassan, 1982; Weinstein et Ponseti, 1983). This progression is believed to be governed by the "HueterVolkmann Law" (Hueter, 1862; Volkmann, 1882), which states that growth depends on the amount of compression on the growth plate, is retarded by increased compression and accelerated by reduced compression (Arkin et Katz, 1956; Roaf, 1960; Hert et Liskova, 1964; Gooding et Neuhauser, 1965; McCall et al., 1981; Scoles et al., 1991). Thus, scoliosis would produce asymmetric loading, which would cause asymmetric vertebral growth resulting in a "vicious cycle" (Mente et al., 1997; Mente et al., 1999; Roaf, 1960; Roaf, 1963; Stokes et al., 1996). Because of the interdependence between the mechanical properties of intervertebral discs and adjacent vertebral bone (Keller et al., 1993), this process may also occur in the discs (Stokes et al., 1996). Moreover, muscles undergo these asymmetric loading and might be also implicated in this vicious cycle. But the remaining question is why does scoliosis progress in some people but either does not progress or spontaneously corrects itself in others? Biomarkers of early scoliosis progression are needed for better therapeutic guidance.

Over other medical imaging techniques, magnetic resonance imaging (MRI) has the advantage of not utilizing ionising radiation and of exploring several physical phenomenons such as relaxation times, magnetization transfer, or diffusion. The first paragraph of this chapter introduces these MRI parameters and presents how they are acquired in vivo. The second paragraph presents the studies on the MRI parameters of bone in order to show how these parameters are good candidates for the investigation of the bone health with scoliosis. The third chapter describes the studies on the relationships between MRI parameters and biochemical or mechanical properties of the intervertebral disc in order to demonstrate that MRI offers great potential as a sensitive and non-invasive technique for describing the alterations in biochemical and material properties within scoliotic intervertebral discs. The fourth paragraph focuses on the relationships between MRI parameters and muscle properties, and the possible applications to scoliosis. The last paragraph focuses on the potential of quantitative MRI to become a very important diagnostic and treatment assessment tool in scoliosis. 


\section{Quantitative MRI}

\subsection{NMR phenomenon}

The NMR phenomenon appears when a system of nuclei in a static magnetic field experiences a perturbation. As long as the transverse magnetization exists, an electrical voltage is induced in a dedicated antenna, the coil. The signal intensity, that is the magnitude of the induced voltage, allows the image to be coded. The density and the relaxation of water protons primarily dominate the high soft-tissue contrast of MRI. The proton density represents the hydrogen concentration within the tissue and reflects the water content. The relaxation process of the tissue is described by $\mathrm{T} 1$ that represents the recovery of the longitudinal magnetization and T2 that represents the decay of the transverse magnetization. The spin-lattice relaxation in the rotating frame, $\mathrm{T} 1 \rho$, detects lowfrequency physicochemical interactions between water and extracellular matrix molecules, as well as changes in macromolecular content, without problems of spin dephasing due to inhomogeneous magnetic fields inherent of T2 contrast. The magnetization transfer MT measures the cross-relaxation and chemical exchange processes between free and macromolecule-bound water protons in tissues. Diffusion tensor imaging takes advantage of the thermally induced random Brownian motion that causes microscopic diffusion of water molecules.

\subsection{Acquisition protocol}

Using a MRI 3T whole-body system (Philips Achieva X-Serie), a protocol for quantitative MRI was optimized for the spine (Périé et al., 2006; Recuerda et al., 2012; Manac'h et al., 2012). Images for the quantification of T1 (Figure 1-a) and T2 (Figure 1-b) are acquired using a multiple inversion recovery turbo spin-echo (TSE) sequence for T1 and a multi-echo turbo spin-echo (TSE) sequence for T2. T1 $\rho$ is quantified using a RF-spoiled turbo gradient-echo sequence with six different spin-lock durations varying between $1 \mathrm{~ms}$ and $50 \mathrm{~ms}$. The MTR is obtained using two gradient echo sequences, one with the off-resonance pulse applied at $1100 \mathrm{~Hz}$ down to the free water proton resonance frequency (Ms, Figure 1-c) and the other one without it (Mo, Figure 1-d) (Wang et al., 2010). A spin-echo EPI diffusion-weighted sequence (TR/TE=2000/40 ms, Figure 1-e) with 15 non-collinear diffusion and a b value of $1000 \mathrm{~s} / \mathrm{mm}^{2}$ is used to quantify the apparent diffusion coefficient ADC, the fractional anisotropy FA and the eigenvectors of the diffusion tensor.

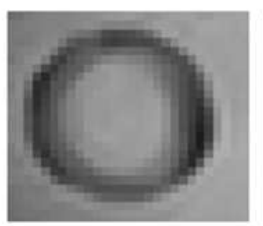

a

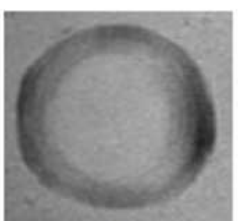

b

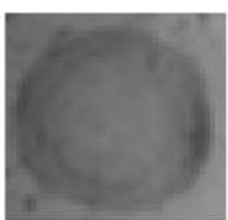

C

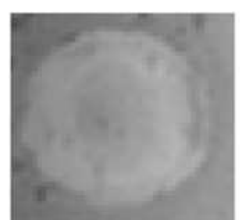

d

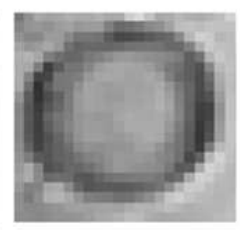

e

Fig. 1. T1 weighted image (a), T2 weighted image (b), MT image with the off-resonance pulse (c), MT image without the off-resonance pulse (d) and Diffusion weighted image (e) for an isolated intervertebral disc (Manac'h et al., 2012). 


\subsection{Parameter computation}

The relaxation times T1 and T2 are extracted from the signal intensity by curve fitting using Equation 1 and Equation 2 respectively (Wright et al., 2008). T1 $\rho$ values are calculated on a pixel-by-pixel basis by a linear regression of intensity data to an exponential decay function using Equation 3 (Johannessen et al., 2006). MT ratio is calculated from Equation 4 (Henkelman et al., 2001). Diffusion parameters (Tensor D, apparent diffusion coefficient ADC and fraction of anisotropy FA) are calculated using Equations 5-7 (Le Bihan et al., 1986; Kingsley et al., 2006). Fibres directions are obtained, in a pixel-by-pixel computation, from the corresponding eigenvalues and eigenvectors of the diffusion tensor (Figure 2).

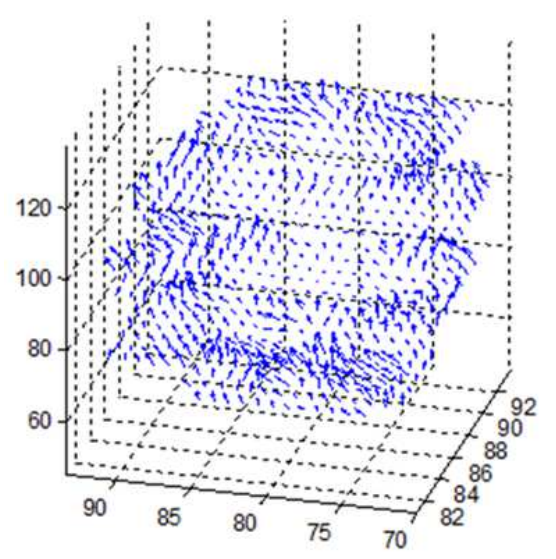

Figure 2: 3D mapping of Diffusion eigenvectors within the intervertebral disc.

$$
\mathrm{SI}_{\mathrm{TI}}=\mathrm{S}_{0} \cdot\left\{1-(1-\cos (\alpha)) \mathrm{E}_{\mathrm{TI}}\left(1-\mathrm{E}_{\mathrm{TW}} \mathrm{f}^{\mathrm{N}}\left(1-\frac{\mathrm{E}_{\mathrm{TE} / 2}}{2}\right)\right)\right\}
$$

with $\mathrm{f}(\mathrm{x})=1-\mathrm{E}_{\mathrm{TE}} \cdot \mathrm{x}, \quad \mathrm{E}_{\mathrm{TI}}=\mathrm{e}^{-\frac{\mathrm{TI}}{\mathrm{T} 1}}, \quad \mathrm{E}_{\mathrm{TW}}=\mathrm{e}^{-\frac{\mathrm{TW}}{\mathrm{T} 1}}, \quad \mathrm{E}_{\mathrm{TE}}=\mathrm{e}^{-\frac{\mathrm{TE}}{\mathrm{T} 1}}$ and $\mathrm{N}=8$

$$
\mathrm{SI}_{\mathrm{TE}}=\mathrm{SI}_{(\mathrm{TE}=0)} \cdot \mathrm{e}^{-\mathrm{TE} / \mathrm{T} 2}
$$

Where SI is the signal intensity, TW is the time in ms between the last refocusing pulse and the next inversion pulse, and $\mathrm{N}$ is the number of refocusing pulses.

$$
\begin{gathered}
\mathrm{S}(\mathrm{TSL})=\mathrm{S}_{0} \mathrm{e}^{-\mathrm{TSL} / \mathrm{T} 1 \rho} \\
\mathrm{MTR}=\frac{\mathrm{M}_{0}-\mathrm{M}_{\mathrm{S}}}{\mathrm{M}_{0}} \\
{\left[\begin{array}{c}
\ln \left(\frac{S I_{\boldsymbol{b}}}{S I_{\boldsymbol{b}=0}}\right)^{1} \\
\vdots \\
\ln \left(\frac{S I_{\boldsymbol{b}}}{S I_{\boldsymbol{b}=0}}\right)^{6}
\end{array}\right]=-\left[\begin{array}{cccccc}
b_{x x}{ }^{1} & 2 b_{x y}{ }^{1} & 2 b_{x z}{ }^{1} & b_{y y}{ }^{1} & 2 b_{y z}{ }^{1} & b_{z z}{ }^{1} \\
\vdots & \vdots & \vdots & \vdots & \vdots & \vdots \\
b_{x x}{ }^{6} & 2 b_{x y}{ }^{6} & 2 b_{x z}{ }^{6} & b_{y y}{ }^{6} & 2 b_{y z}{ }^{6} & b_{z z}{ }^{6}
\end{array}\right] \times\left[\begin{array}{c}
D_{x x} \\
D_{x y} \\
D_{x z} \\
D_{y y} \\
D_{y z} \\
D_{z z}
\end{array}\right]}
\end{gathered}
$$




$$
\begin{gathered}
A D C=\frac{\lambda_{1}+\lambda_{2}+\lambda_{3}}{3} \\
\mathrm{~F}_{\mathrm{A}}=\sqrt{\frac{3\left[\left(\lambda_{1}-\mathrm{ADC}\right)^{2}+\left(\lambda_{2}-\mathrm{ADC}\right)^{2}+\left(\lambda_{3}-\mathrm{ADC}\right)^{2}\right]}{\left[\lambda_{1}^{2}+\lambda_{2}^{2}+\lambda_{3}^{2}\right]}}
\end{gathered}
$$

Where SI represents the signal intensity at the corresponding b-value $\boldsymbol{b}$ and $b_{i j}$ represent the projected $b$-value obtained from the diffusion-encoding directions, $\lambda i$ are the eigenvalues of the diffusion tensor D.

\section{MRI parameters of bone}

It has been shown that for early scoliosis, the mechanical properties of the apical vertebral body are modified (Périé et al., 2001). Computed tomography (CT) examination was performed on eleven girls presenting idiopathic scoliosis. A finite element mesh of the vertebral body, the mapping of the $\mathrm{CT}$ number on each $\mathrm{CT}$ slice and predictive relationships between the CT number and the Young's modulus of bone (Hobatho et al., 1996) allowed the $3 \mathrm{D}$ analysis of the bone mechanical property distribution within the vertebral body. Geometrical and mechanical centres were calculated. Compared to the geometrical centre, the mechanical centre was shifted forward to the concavity in the coronal plane and to the back in the sagittal plane. This modification of the mechanical properties seemed to appear in the scoliotic vertebral body before any geometrical deformation such as wedging. Moreover, the comparison between the centre shift forward and the one year curvature evolution wearing the Cheneau-Toulouse-Munster brace showed that if the shift forward was important then the curvatures were stabilised or aggravated, and if the shift forward was low then the curvatures were reduced. This parameter has the potential of being a biomarker of the progression of scoliosis. However, its measurement requires invasive CT acquisitions that cannot be used for longitudinal studies of adolescents with idiopathic scoliosis. Thus the question is can we determine this biomarker from a non invasive medical image technique such as MRI (Figure 3)?
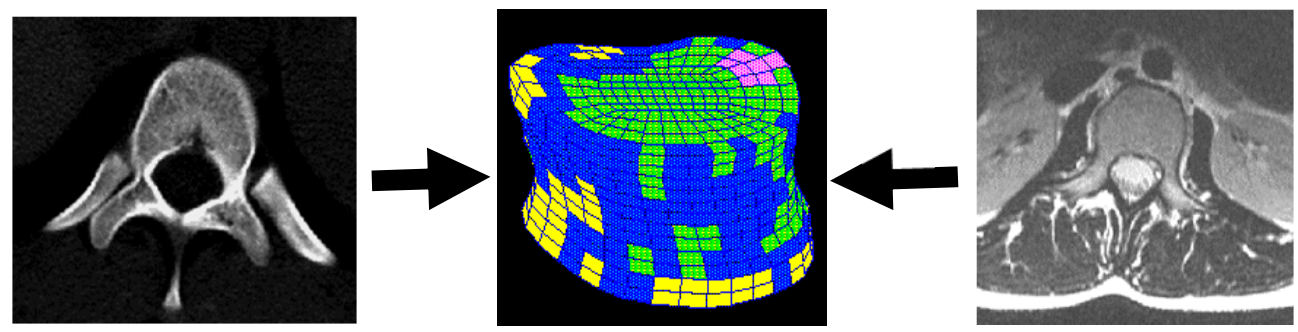

Fig. 3. 3D mapping of the mechanical properties of vertebral bone from CT images (left). Is it possible to determine these properties from MR images (right)?

MRI has the potential to give information pertaining to both trabecular bone mineral density (BMD) and bone structure. The effective transverse relaxation time $\mathrm{T} 2 *$ of bone marrow, measured from the signal intensity (Equation 8), is shortened in the presence of trabecular bone. The variations in magnetic susceptibility at the interface of solid and soft tissues causes local magnetic field inhomogeneities which induce a dephasing of the transverse magnetization, and thus a change in the effective transverse relaxation time $\mathrm{T} 2{ }^{*}$. Strong 
correlations were found between BMD, as measured from $\mathrm{CT}$, and $1 / \mathrm{T} 2 *$, as measured from MRI, on cadaveric human vertebral bodies (Majumdar et al., 1991). Correlations were also found between the Young's modulus E and 1/T2 on cancellous bone (Chung et al., 1993), and between $\mathrm{T}^{*}$ and 1/E (Equation 9, Jergas et al., 1995). A combination of 1/T2* and MRIderived bone volume fraction further improved the prediction of yield stress and ultimate strength (Lammentausta et al., 2006).

$$
\begin{gathered}
S I=I_{0} e^{-T E / T 2^{*}} \\
\frac{1}{\mathrm{E}}=\mathrm{a} T_{2}^{*}+\frac{\mathrm{b}}{T_{2}^{*}}+\mathrm{n}
\end{gathered}
$$

$\mathrm{T}^{*}$ is not a simple derivate of bone density, it is influenced by the number, thickness, geometric shape and spatial arrangement of trabecular elements in a defined volume. Structural parameters (fractional area, trabecular width, trabecular number, fractal dimension, trabecular spacing) depend on the pulse sequence (gradient echo or spin-echo) and echo time used to obtain the MR images, and also on the choice of the threshold used to segment the images (Majumdar et al., 1995; Link et al., 1998). Cortical bone mineral content, trabecular bone mineral density and volume fraction, trabecular thickness and number, and fractal dimension all decreased with age (Wehrli et al., 1995; Majumdar et al., 1997).

However, this use of MRI for the assessment of mechanical properties of bone tissues was applied only to the effect of osteoporosis. As CT measurements showed changes in the mechanical properties of bone with early scoliosis (Périé et al., 2001), and as CT measurements were found correlated to MRI measurements (Majumdar, 1991), MRI and T2* mapping should be an effective tool to assess the changes in bone with idiopathic scoliosis. The longitudinal relaxation time $\mathrm{T} 1$ has been measured recently from ultrashort TE MR imaging on bovine femur and this parameter was found to be sensitive to the water content within the bone tissue (Kokabi et al., 2011). However, ultrashort TE MRI reduces the signal to noise ratio and might be difficult to apply in vivo on scoliotic patients.

\section{MRI parameters of intervertebral discs}

Spinal deformities affect both the structural and the biochemical composition of the intervertebral disc (Bushell et al., 1979; Jongeleenen et al., 2006) and lead to its degeneration. Adolescent Idiopathic Scoliosis is marked by a wedging of the intervertebral disc linked with a displacement of the nucleus pulposus (Figure 4, Périé et al., 2001) and changes in the glycosaminoglycan and water content repartition (Urban et al., 2001; Schenzka et al., 1991; Kouwenhoven et Castelein, 2008).

The measure of the concentrations of specific molecules reflecting matrix synthesis and degradation in normal and scoliotic intervertebral discs showed higher collagen Type II synthetic levels and increased total protein content with no matrix turnover (Antoniou et al., 1998). These results suggest that scoliotic changes are due to an altered and ineffective synthetic response to a pathologic mechanical environment. These biochemical changes within the intervertebral disc are known to be related to the MR parameters T1, T2, MT and ADC. 

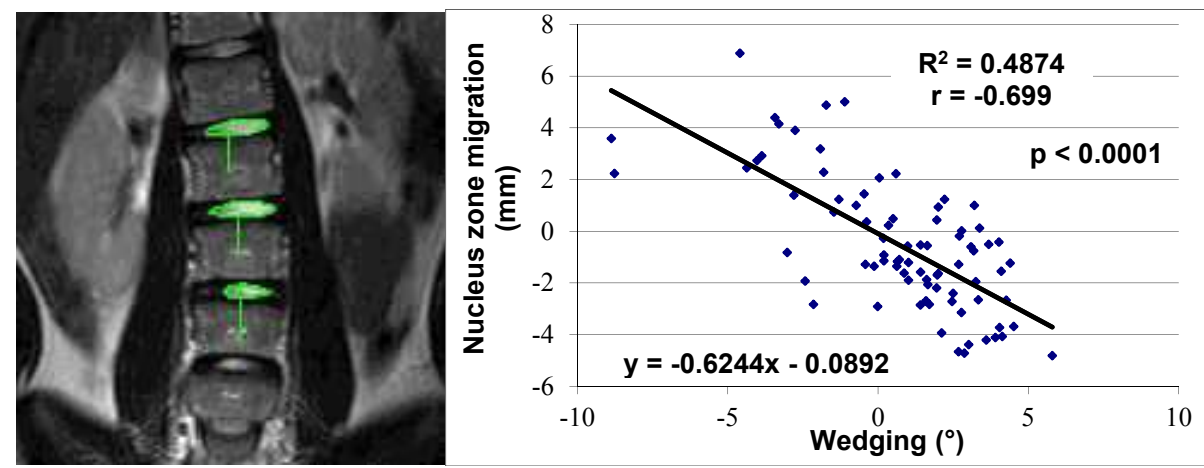

Fig. 4. Segmentation of the nucleus pulposus zone from T2-weighted images (left) and correlation between nucleus zone migration and intervertebral wedging in adolescent idiopathic scoliosis (Périé et al., 2001).

In the intervertebral disc in vitro, $\mathrm{T} 1, \mathrm{~T} 2$ and MT were found to be correlated to the water content and GAG content, but not to the collagen content or percentage of denatured type II collagen (Tertti et al., 1991; Antoniou et al., 1998), whereas the apparent diffusion coefficient was directly related to proteoglycans content and inversely related to collagen denaturation (Antoniou et al., 2004). However, a moderate negative correlation was found between 1/T2 and water content whereas there was no significant correlation between 1/T2 and proteoglycan content (Weidenbaum et al., 1992). In normal nucleus pulposus, T1 and T2 decrease with age, with no significant correlation between proton density and age (Jenkins et al., 1989), but with a significant correlation between signal intensity and age (Sether et al., 1990). Changes in water content due to degeneration have a greater influence on T1 in the nucleus pulposus than in the annulus fibrosus (Chatani et al., 1993; Antoniou et al., 1998). In vitro collagenase treatment significantly increased the proportion of denatured collagen, and decreased T1, T2 and ADC, with no significant effect on MT (Antoniou et al., 2004). The diffusion parameters were found to be more sensitive to the trypsin digestion of isolated discs than the relaxation times $\mathrm{T} 1$ and $\mathrm{T} 2$. However, these parameters were sensitive to the hydration process (Manac'h et al., 2012). Significant differences were found on the MR parameters by region (higher T1, T2 and ADC in the nucleus than in the annulus), loading state (higher T1 and ADC in the loaded disc than in the unloaded), Thompson grade (T2, ADC), and direction of diffusion (Chiu et al., 2001). After compression, the water diffusion either increases in creep (load steps) experiments (Chiu et al., 2001), or decreases in stressrelaxation (displacement steps) experiments (Burstein et al., 1993). The orientations of diffusion anisotropy in the annulus fibrosus exhibited a layered morphology that agreed with light micrographs of the corresponding samples, and the behaviour of the orientation angles was consistent with the known collagen fibber architecture (Hsu and Setton, 1999). All these studies showed that the MRI parameters are sensitive to both the biochemical content and the structure of the intervertebral disc.

Some authors have shown that MRI offers great potential as a sensitive and non-invasive technique for describing the alterations in the mechanical properties of intervertebral discs or cartilage. Correlations were found in cartilage between the longitudinal relaxation time T1gd as measured by Gadolinium-Enhanced MRI and the local stiffness as measured by 
mechanical indentation (Samosky et al., 2005), or unconfined compression (Chen et al., 2003; Kurkijarvi et al., 2004; Nieminen et al., 2004; Lammentausta et al., 2006). The spin-lock longitudinal relaxation time T1 $\rho$ was strongly correlated to the compressive modulus and the hydraulic permeability in cartilage (Wheaton et al., 2005) and to the swelling pressure in human nucleus pulposus (Nguyen et al., 2008). On bovine nucleus pulposus, significant correlations were found between the hydraulic permeability and the relaxation times or the diffusion trace (Périé et al., 2006). Moreover, the compressive modulus of nucleus pulposus was found to be correlated to the longitudinal relaxation times T1 and T1 $\rho$, while the hydraulic permeability of annulus fibrosus was found to be inversely correlated to T1 $\rho$ (Mwale et al., 2008). Multi linear regressions showed that 50 to $80 \%$ of the compressive modulus and the permeability of isolated intervertebral discs can be explained by MRI parameters (T1, T2, MT, ADC, FA) within both the annulus fibrosus and the nucleus pulposus. However, multicollinearity was present among the independent variables, suggesting that T1 and T2 were likely candidates for elimination in the equation. Thus the compressive modulus and the permeability of isolated intervertebral discs can be assessed mostly by MT and diffusion sequences (Recuerda et al., 2012).

However, before the use of this technique to quantify the mechanical properties of intervertebral discs in vivo on patients suffering from various spine diseases, the relationships have to be defined for each degeneration type of the tissue that mimics the pathology (Recuerda et al., 2012). Another issue is that the intervertebral disc is submitted to complex loading stimuli in vivo. Does the mechanical loading of the disc influence the MRI acquisition of the relaxation times, magnetization transfer and diffusion parameters? An apparatus allowing the compression of isolated intervertebral discs was designed and manufactured in ABS. Intervertebral discs were dissected from fresh young bovine tail, measured for their thickness and submitted to static compression (5, 10, 20 and 40\% deformation) just before the MRI acquisition. The short term static compression of the intervertebral disc did not lead to any significant change of the MRI parameters, except for the diffusion that decreased in the direction of the compressive stress (Manac'h et al., 2012).

Quantitative MRI of the intervertebral disc was also performed in vivo. Diurnal variations, significantly less pronounced in degenerative than in normal intervertebral disc, were characterized by lower T1 and higher T2 measured in the evening than in the morning (Karakida et al., 2003; Boos et al., 1993), whereas lower T2 were found after bed rest (LeBlanc et al., 1994). T2 and ADC turned out to be sensitive parameters in investigating changes in the MR characteristics of the intervertebral disc matrix between morning and evening (Ludescher et al., 2008). A significant and strong correlation was found between in vivo T1 $\rho$ values and discography opening pressure measurements suggesting that $\mathrm{T} 1 \rho$ is a quantitative measure of degeneration (Borthakur et al., 2011). A relationship was also found between in vivo MRS spectroscopy (water content, proteoglycan content), imaging parameters (T1 $\rho$, Pfirrmann Grade), and discography results suggesting that MRSquantified water, proteoglycans and MR T1 $\rho$ relaxation time may potentially serve as biomarkers of symptomatic intervertebral disc degeneration (Zuo et al., 2011). An abnormal loading representing an increase of the intradiscal pressure from $0.5 \mathrm{MPa}$ to $1-2 \mathrm{MPa}$ was created in vivo by walking for $1 \mathrm{~h} 30$ with a back pack of $20 \mathrm{~kg}$. Quantitative MRI was done on the lumbar spine before and after the loading that entailed a significant decreased in T1 while T2 increased significantly (Table 1, preliminary work from the author, unpublished data). Mean ADC and MT values were constant. Qualitatively, there were differences in the 
distribution of each parameter, even for ADC, confirmed by the smaller slope of the cumulative histogram after loading (Figure 5).

\begin{tabular}{|c|c|c|}
\hline & Before loading & After loading \\
\hline $\mathrm{T} 1$ & & \\
\hline $\mathrm{T} 2$ & - & \\
\hline $\mathrm{ADC}$ & & \\
\hline MT & & \\
\hline
\end{tabular}

Table 1: Mapping of the L4-L5 intervertebral disc of a healthy subject, before and after the loading that consisted in walking with a $20 \mathrm{~kg}$ back pack for one hour.
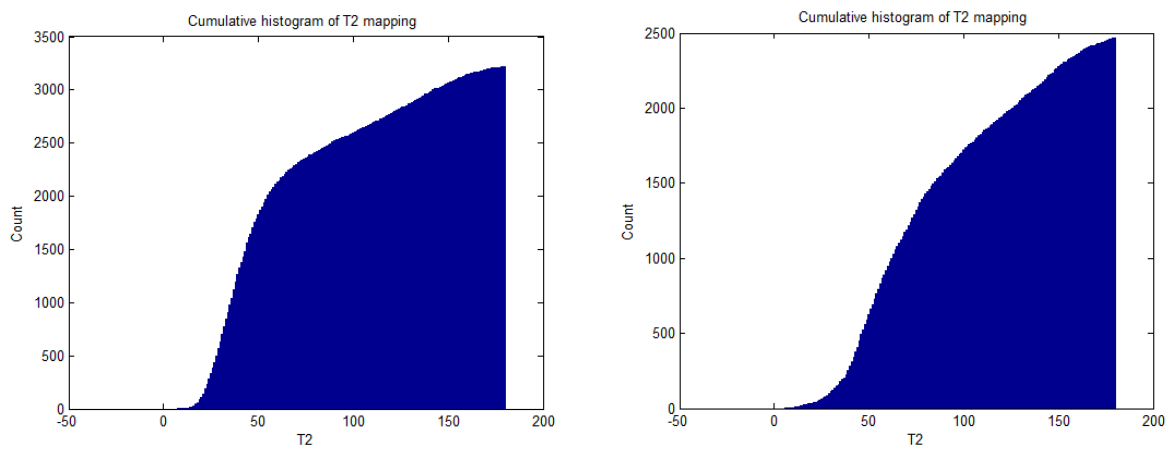

Fig. 5. Cumulative histogram of T2 in L5/S1 intervertebral disc before (left) and after (right) loading.

\section{MRI parameters of muscles}

Idiopathic scoliosis disrupts the symmetry of the paraspinal muscle activities, decreases the total mechanical work, increases the oxygen consumption and energy cost and decreases muscles efficiency (Tsai et al.; Mahaudens et al.; Khosla et al., 1980). Biopsy studies shows abnormalities regarding the architecture of the paraspinal muscles of scoliotic subjects (Kennelly et Stokes, 1993), their protein synthesis (Gibson et al., 1988) and their muscle fiber type composition (Meier et al., 1997; Mannion et al., 1998; Sirca et al., 1985). In scoliotic subjects, the proportion of type I muscle fibers is smaller on the concave side than on the 
convex side whereas in normal subjects, a symmetric distribution is observed. Moreover, the cross sectional area of type II muscle fibers is larger on the concave side than on the convex side (Mannion et al., 1998; Bylund et al., 1987; Zetterberg et al., 1983). A larger electromyographic (EMG) signal has often been observed in idiopathic scoliosis on the convex side of the curves (Odermatt et al., 2003; Cheung et al., 2006). However, during isometric efforts in extension, EMG parameters could not discriminate between the back muscles of scoliotic subjects and those of control subject regarding fiber type composition, neuromuscular efficiency and muscle fatigue at the level of the apex, maybe due to compensatory strategies at lower level of the spine (Goudreault et al., 2005).

Several specific magnetic resonance imaging (MRI) techniques were developed for muscle applications, such as MR spectroscopy to quantify adenosine- 5 triphosphate, lactates or creatine (Jeneson et Bruggeman, 2004) and MR elastography (Bensamoun et al., 2007, 2008) to visualize and measure the deformation waves within the tissue submitted to mechanical excitations and to assess their mechanical properties. However, MR spectroscopy is limited by a low resolution, the acquisition of a single voxel and results difficult to interpret. A special apparatus is needed for MR elastography to create the vibrations, which means extra cost and time to prepare the patient.

Studies on the human skeletal muscles demonstrated that ADC may be used to analyze the spatial architecture (Heemskerk et al., 2005) and to indicate the change in micro-structure associated with passive extension and contraction (Hatakenaka et al., 2008). Also, T2 increases with the muscle activation as a result of the shift of the osmotically driven intracellular fluid, and could be used to demonstrate aberrant muscle activation (Kinusaga et al., 2006; Patten et al., 2003). It is well established that MR parameters are linked to the mechanical and biochemical properties of cartilage tissues. Does a relationship exist between the mechanical properties and the MR parameters of muscles?

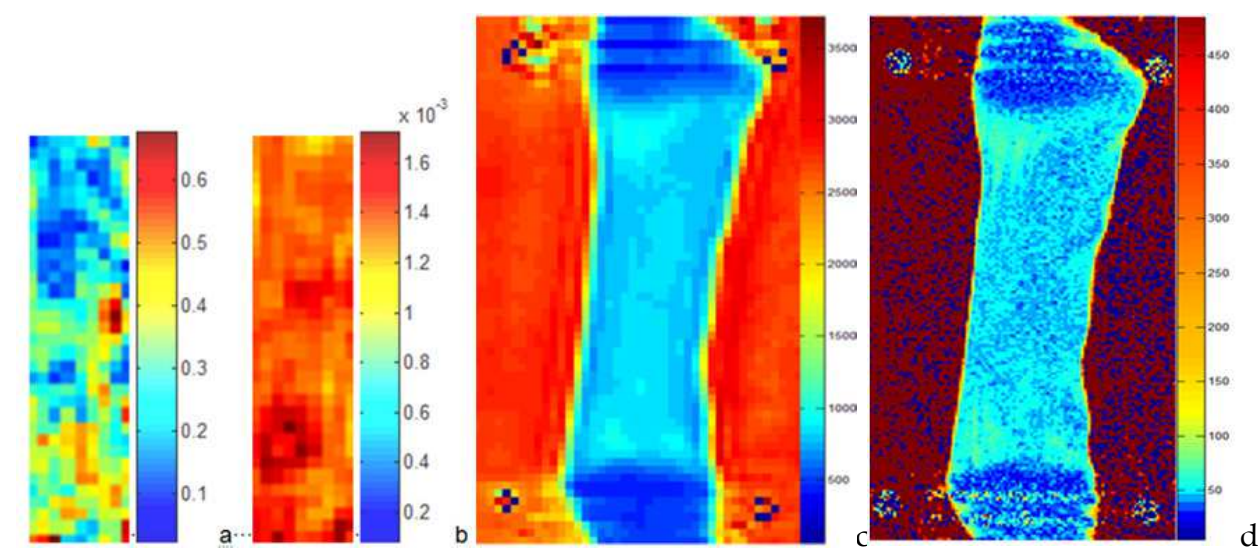

Fig. 6. FA map (a), ADC map (b), T1 map (c) and T2 map (d) of the rabbit semi-membranous muscle (rigor mortis).

Leg and arm muscles of adult rabbits were dissected, and tested 12 hours post mortem, in a state of rigor mortis, or 72 hours post mortem, in a state of post-rigor mortis (Grenier et al., 2012). The tests consisted of a quantitative MRI acquisition (T1, T2, MTR, ADC, FA, Figure 
6) and a uniaxial tensile test until failure (Young's modulus E). The results showed that multiple linear regressions exist between E, MTR and ADC (Equation 10) and that MRI would be a sensitive and non-invasive tool for the characterisation of muscle properties in the back muscles.

$$
\mathrm{E}[\mathrm{Pa}]=(36,6[\mathrm{~Pa}]-37,5[\mathrm{~Pa}] \times \mathrm{MTR}[\%]) \times 10^{4}-128,1 \times 10^{12}\left[\mathrm{Kg} / \mathrm{s}^{*} \mathrm{~m}^{3}\right] \times \mathrm{ADC}\left[\mathrm{m}^{2} / \mathrm{s}\right]
$$

\section{6. qMRI in idiopathic scoliosis}

MRI can be a powerful tool for the diagnosis of spine pathologies and can potentially help to monitor their progression in vivo (Majumdar, 2006; Endean et al., 2010, Mwale et al., 2008). For instance, MRI gives reliable non-invasive 3D images of the intervertebral disc (Pfirmann et al., 2001) allowing longitudinal follow-up studies and T2-weighted images are used to assess the intervertebral disc degeneration (Majumdar et al., 2006; Pfirmann et al., 2001; Antoniou et al., 1998), but is limited to the detection of late stages of the spine pathologies (Pfirmann et al., 2001).

The distribution of the MRI signal intensity was not exploited so far to analyze the local changes in the intervertebral disc structure and biochemistry with degeneration. Only the mean signal intensity or disc height or disc volume were analysed from clinical images. A prospective study was realized on the MR T2-weighted images of 32 volunteers with scoliosis and 15 control volunteers (Figure 9).
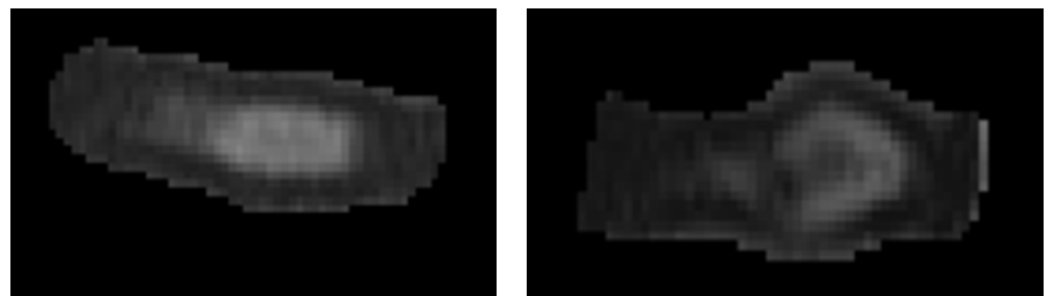

Fig. 9. Segmented intervertebral discs for control (left) and scoliosis (right) volunteer on sagittal T2-weighted images.

The pathologic subjects were separated into two severity groups. The Gaussian distribution of the MRI signal intensity was analyzed by normalized histograms. The following descriptive statistics were computed within the intervertebral disc, nucleus pulposus and annulus fibrosus of each subject in order to analyze the Gaussian distribution of their MR signal intensity. The standard error of the mean depicts how sample mean approximates the true population mean. The confidence interval of the mean describes the range in which the true population mean will fall for a percentage of all possible samples drawn from the population. The sum of square defines the sum of squared deviations from the mean. The Skewness gives an index on the symmetry of the Gaussian distribution of the histogram. The Kolmogorov-Smirnov distance is the maximum cumulative distance between the histogram distribution and the Gaussian distribution of intensity data. Their 75th percentile was also computed. The center weighted by the MRI intensity within the intervertebral disc and the volume ratio of the nucleus pulposus within the total intervertebral disc were computed. There were significant variations of indices between scoliosis and control groups 
and between low and high severity groups. These newly developed MRI parameters allowed the quantitative analysis of spinal deformities involved in scoliosis of different severities (Gervais et al., 2012).

This promising technique was limited by the low resolution of the clinical T2-weighted images, which induces considerable segmentation errors or a poor and limited visual interpretation. Acquiring high resolution matrices is time consuming and induces high cost. A new mathematical technique based on multidimensional Dual-Kriging was developed (Aissiou et al., 2012). T1, T2, MTR and Diffusion sequences were used to acquire two different matrices with different sizes (128x128 and 256x256). The Kriging system parameters and the polynomial degree were optimized, and low resolution images (128x128) were interpolated to high resolution (256x256) in 2D (Figure 10-12) and 3D (Figure 13). Kriging system provided relatively high performances and low error within the regions of interest. Components contours tend to be corrected and better defined, following the Kriging interpolation. Progressive Dual-Kriging is a flexible technique that can be optimized to interpolate 2D and 3D qMRI data based on the signal distribution. The computation is extremely fast and the interpolation is better fitted to the signal distribution as opposed to the Zero-Padding technique.
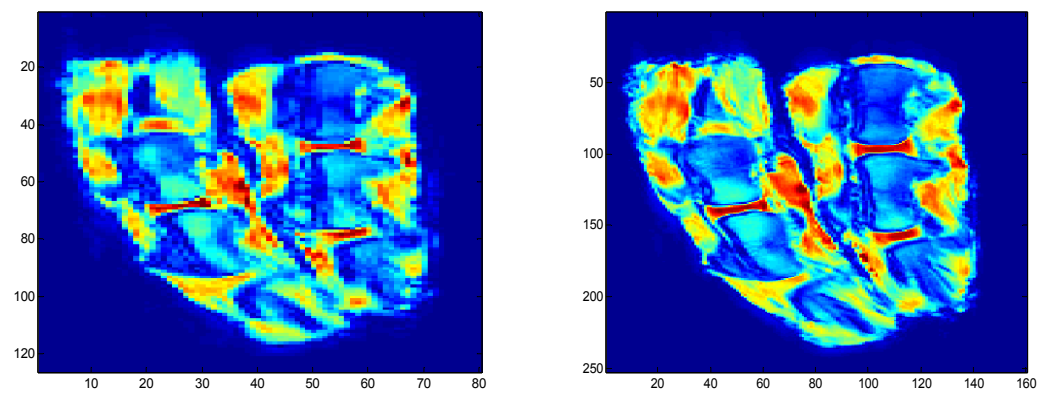

Fig. 10. T1 before kriging (left) and after kriging (right) of two bovine tail segments.
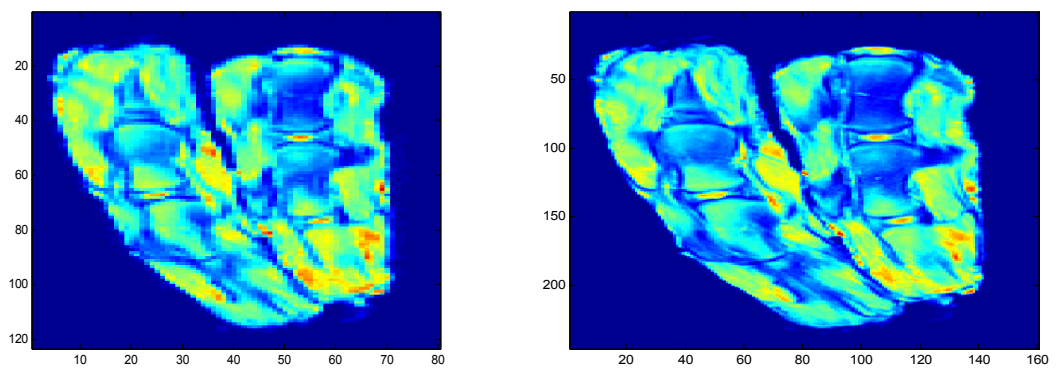

Fig. 11. T2 before kriging (left) and after kriging (right) of two bovine tail segments. 

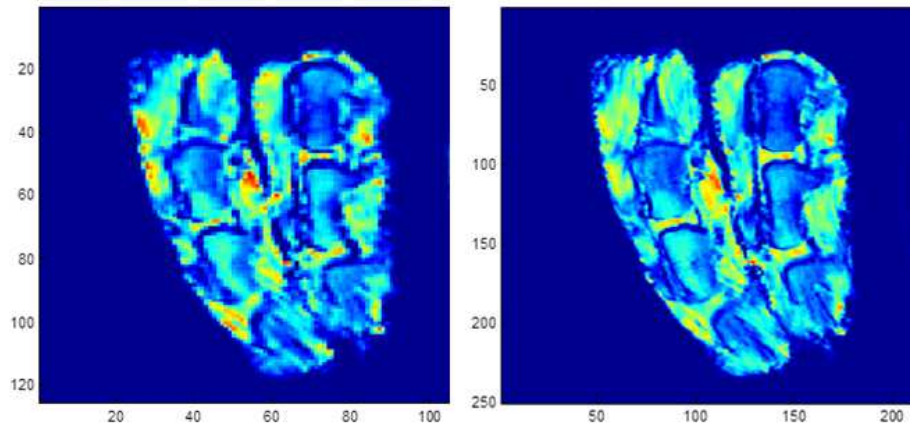

Fig. 12. MTR before kriging (left) and after kriging (right) of two bovine tail segments.
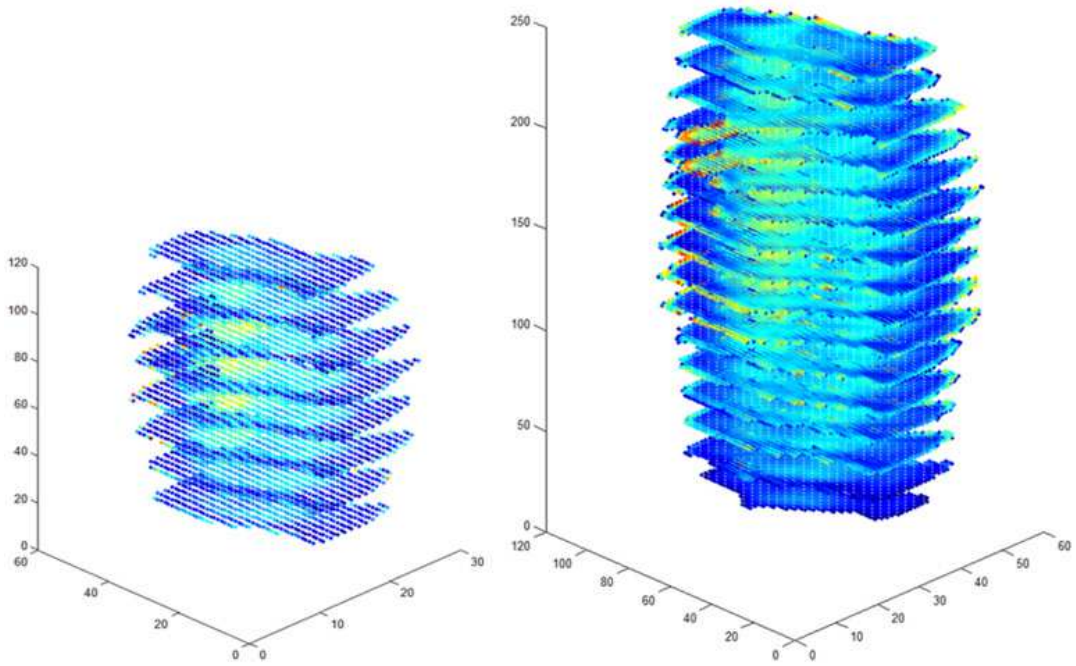

Figure 13: Non-parametric volume Kriging (with signal inversion and substraction) of a human intervertebral disc from an in vivo quantitative MRI acquisition (T2 map).

The two techniques presented in this paragraph, analysis of the MR signal distribution within the tissue of interest using descriptive statistics of histograms and kriging of the images to increase their resolution, can be applied to quantitative MR images of scoliotic spines. A quantitative MRI protocol takes about 40 minutes in vivo, including T1 or T1rho, T2, MT and diffusion sequences, 8 sagittal slices $3 \mathrm{~mm}$ thick, resolution of $1 \mathrm{mmx} 1 \mathrm{~mm}$. This resolution can be improved automatically during the post-treatment of the images. Automatic segmentation of the discs components can be done on the color maps of the relaxation times and MT ratio, not yet on the diffusion maps, not yet on the muscles. The parameters are automatically calculated, and the follow-up of these parameters on scoliotic patients would confirm or reject that they are biomarkers of the progression of the pathology. 


\section{Conclusion}

Quantitative MRI associated with kriging techniques to improve the image resolution, automatic segmentation techniques and tools for the analysis of the distribution of each parameter in a region of interest has the potential to become a very important diagnostic and treatment assessment tool in scoliosis. This region of interest can be located within the intervertebral disc, annulus fibrosus or nucleus pulposus, within the vertebral bone, or within the muscle, for a same MRI acquisition in the sagittal plane. It could replace discography before fusion surgery, help identify the degenerated tissues, help compare different types of surgery with respect to future adjacent degeneration, or be used to monitor the changes after any treatment proposed. Moreover, these MRI parameters could be identified as biomarkers of scoliosis progression.

\section{Acknowledgment}

The author would like to thank Maximilien Recuerda, Julien Gervais, Yann-Guirec Manac'h, Mohamed Aissiou, for their contribution to the works presented in this chapter, Guillaume Gilbert and Gilles Beaudoin for their support for all MRI data acquisitions and analysis. The work from the author presented in this chapter was supported in part by the NSERC (Discovery grant), the Scoliosis Research Society (Young Investigator Research grant), the CHU Sainte-Justine (Start-up grant) and the Ecole Polytechnique de Montreal (Start-up grant).

\section{References}

Aissiou M., Gilbert G., Gervais J., Beaudoin G., Trocchu F., Périé D., Progressive Dual Kriging for $2 \mathrm{D}$ and $3 \mathrm{D}$ qMRI data interpolation. Medical Physics, submitted.

Antoniou J, Pike GB, Steffen T, et al. Quantitative magnetic resonance imaging in the assessment of degenerative disc disease. Magn Reson Med. 1998;40(6):900-7.

Arkin AM, Katz JF. (1956), The effects of pressure on epiphyseal growth. The mechanism of plasticity of growing bone. J Bone Joint Surg [Am] 38:1056-76.

Bensamoun, S. F., Ringleb, S. I., Chen, Q., Ehman, R. L., An, K. N., and Brennan, M., 2007, "Thigh Muscle Stiffness Assessed with Magnetic Resonance Elastography in Hyperthyroid Patients before and after Medical Treatment," J Magn Reson Imaging, 26(3), pp. 708-13.

Bensamoun, S. F., Glaser, K. J., Ringleb, S. I., Chen, Q., Ehman, R. L., and An, K. N., 2008, "Rapid Magnetic Resonance Elastography of Muscle Using One-Dimensional Projection," J Magn Reson Imaging, 27(5), pp. 1083-8.

Bjerkreim I, Hassan I. (1982), Progression in untreated idiopathic scoliosis after end of growth. Acta Orthop Scand 53:897-900.

Borthakur A, Maurer PM, Fenty M, Wang C, Berger R, Yoder J, Balderston RA, Elliott DM. $\mathrm{T} 1 \rho$ magnetic resonance imaging and discography pressure as novel biomarkers for disc degeneration and low back pain. Spine 2011;36(25):2190-6.

Bushell GR, Ghosh P, Taylor TK, Sutherland JM. The collagen of the intervertebral disc in adolescent idiopathic scoliosis. J Bone Joint Surg Br. 1979;61-B(4):501-8.

Bylund P, Jansson E, Dahlberg E, Eriksson E: Muscle fiber types in thoracic erector spinae muscles. Fiber types in idiopathic and other forms of scoliosis. Clin Orthop 1987:222-228. 
Chen CT, Fishbein KW, Torzilli PA, Hilger A, Spencer RG, Horton WE. Matrix fixed-charge density as determined by magnetic resonance microscopy of bioreactor-derived hyaline cartilage correlates with biochemical and biomechanical properties. Arthritis Rheum 2003, 48(4):1047-56.

Cheung J, Veldhuizen AG, Halberts JP, Sluiter WJ, Van Horn JR. Geometric and electromyographic assessments in the evaluation of curve progression in idiopathic scoliosis. Spine 2006;31:322-9.

Chung H, Wehrli FW, Williams JL, Kugelmass SD. Relationship between NMR transverse relaxation, trabecular bone architecture, and strength. Proc Natl Acad Sci USA 1993, 90(21):10250-4.

Endean A, Palmer KT, Coggon D. Potential of Magnetic Resonance Imaging Findings to Refine Case Definition for Mechanical Low Back Pain in Epidemiological Studies: A Systematic Review. Spine (Phila Pa 1976). 2010.

Gaudreault N, Arsenault AB, Larivière C, DeSerres SJ, Rivard CH. Assessment of the paraspinal muscles of subjects presenting an idiopathic scoliosis: an EMG pilot study. BMC Musculoskelet Disord. 2005 Mar 10;6:14.

Gervais J., Périé D., Aubin C.E., Parent S., Labelle H., MRI signal distribution within the intervertebral disk as a descriptive factor of spine deformities. Spine, submitted.

Gibson JNA, McMaster MJ, Scrimgeour CM, Stoward PJ, Rennie MJ: Rates of protein synthesis in paraspinal muscles: Lateral disparity in children with idiopathic scoliosis. Clinical Science 1988, 75:79-83.

Gooding CA, Neuhauser EBD. (1965), Growth and development of the vertebral body in the presence and absence of normal stress. AJR Am J Roentgenol 93:388-94.

Grenier R., Gilbert G., Beaudoin G., Curnier D., Périé D., Assessment of mechanical properties of muscles using Quantitative MRI. Journal of Biomechanical Engineering, submitted.

Hatakenaka, M., Yabuuchi, H., Matsuo, Y., Okafuji, T., Kamitani, T., Setoguchi, T., Nishikawa, K., and Honda, H., 2008, "Effect of Passive Muscle Length Change on Apparent Diffusion Coefficient: Detection with Clinical Mr Imaging," Magn Reson Med Sci, 7(2), pp. 59-63.

Heemskerk, A. M., Strijkers, G. J., Vilanova, A., Drost, M. R., and Nicolay, K., 2005, "Determination of Mouse Skeletal Muscle Architecture Using Three-Dimensional Diffusion Tensor Imaging," Magn Reson Med, 53(6), pp. 1333-40.

Henkelman, R.M., Stanisz, G.J., and Graham, S.J. 2001. Magnetization transfer in MRI: a review. NMR in Biomedicine 14:57-64.

Hert J, Liskova M. (1964), Regulation of the longitudinal growth of the long bone by mechanical influence. Acta Univ Carol Med 20(Suppl):32-4.

Hueter C. (1862), Anatomische Studien an den Extremitaetengelenken Neugeborener und Erwachsener. Virkows Archiv Path Anat Physiol 25:572-99.

Jeneson, J. A., and Bruggeman, F. J., 2004, "Robust Homeostatic Control of Quadriceps Ph During Natural Locomotor Activity in Man," Faseb J, 18(9), pp. 1010-2.

Jergas MD, Majumdar S, Keyak JH, Lee IY, Newitt DC, Grampp S, Skinner HB, Genant HK. Relationships between young modulus of elasticity, ash density, and MRI derived effective transverse relaxation T2* in tibial specimens. J Comput Assist Tomogr 1995, 19(3):4729. 
Johannessen W, Auerbach JD, Wheaton AJ, et al. Assessment of human disc degeneration and proteoglycan content using T1rho weighted magnetic resonance imaging. Spine 2006:31:1253-1257.

Jongeleenen CMJ. Biomechanics in the intervertebral disc : A literature review. BMTE 0618. 2006:24.

Keller T.S., Ziv I., Moeljanto E., Spengler D.M. (1993), Interdependence of lumbar disc and subdiscal bone properties: a report of the normal and degenerated spine. J Spinal Disord. 6(2):106-13.

Kennelly KP, Stokes MJ: Pattern of asymmetry of paraspinal muscle size in adolescent idiopathic scoliosis examined by real-time ultrasound imaging. A preliminary study. Spine 1993, 18(7):913-917.

Khosla, S., Tredwell, S. J., Day, B., Shinn, S. L., and Ovalle, W. K., Jr., 1980, "An Ultrastructural Study of Multifidus Muscle in Progressive Idiopathic Scoliosis. Changes Resulting from a Sarcolemmal Defect at the Myotendinous Junction," J Neurol Sci, 46(1), pp. 13-31.

Kingsley, P.B. 2006. Introduction to diffusion tensor imaging mathematics: Part I. Tensors, rotations, and eigenvectors. Concepts in Magnetic Resonance Part A 28A:101-122.

Kingsley, P.B. 2006. Introduction to diffusion tensor imaging mathematics: Part II. Anisotropy, diffusion-weighting factors, and gradient encoding schemes. Concepts in Magnetic Resonance Part A 28A:123-154.

Kinugasa, R., Kawakami, Y., and Fukunaga, T., 2006, "Mapping Activation Levels of Skeletal Muscle in Healthy Volunteers: An Mri Study," J Magn Reson Imaging, 24(6), pp. 14205.

Kokabi N, Bae W, Diaz E, Chung CB, Bydder GM, Du J. of bovine cortical bone: the effect of water loss on the $\mathrm{T} 1$ and $\mathrm{T} 2 *$ relaxation times. Magn Reson Med. 2011 Aug;66(2):476-82.Kouwenhoven JWM, Castelein RM. The Pathogenesis of Adolescent Idiopathic Scoliosis Review of the Literature. Spine. 2008;33(26):2898-908.

Kurkijarvi JE, Nissi MJ, Kiviranta I, Jurvelin JS, Nieminen MT. Delayed gadolinium-enhanced MRI of cartilage (dGEMRIC) and T2 characteristics of human knee articular cartilage: topographical variation and relationships to mechanical properties. Magn Reson Med 2004, 52(1):41-6.

Lammentausta E, Hakulinen MA, Jurvelin JS, Nieminen MT. Prediction of mechanical properties of trabecular bone using quantitative MRI. Phys Med Biol. 2006; 51(23):618798.

Lammentausta E, Kiviranta P, Nissi MJ, Laasanen MS, Kiviranta I, Nieminen MT, Jurvelin JS. T2 relaxation time and delayed gadolinium-enhanced MRI of cartilage (dGEMRIC) of human patellar cartilage at $1.5 \mathrm{~T}$ and $9.4 \mathrm{~T}$ : Relationships with tissue mechanical properties. J Orthop Res 2006, 24(3):366-74.

Le Bihan, D., Breton, E., Lallemand, D., Grenier, P., Cabanis, E., and Laval-Jeantet, M. 1986. MR imaging of intravoxel incoherent motions: application to diffusion and perfusion in neurologic disorders. Radiology 161:401-407.

Link TM, Majumdar S, Lin JC, Newitt D, Augat P, Ouyang X, Mathur A, Genant HK. A comparative study of trabecular bone properties in the spine and femur using high resolution MRI and CT. J Bone Miner Res 1998, 13(1):122-32. 
Ludescher B, Effelsberg J, Martirosian P, Steidle G, Markert B, Claussen C, Schick F. T2- and diffusion-maps reveal diurnal changes of intervertebral disc composition: an in vivo MRI study at 1.5 Tesla. J Magn Reson Imaging. 2008 Jul;28(1):252-7.

Mahaudens, P., and Mousny, M., "Gait in Adolescent Idiopathic Scoliosis. Kinematics, Electromyographic and Energy Cost Analysis," Stud Health Technol Inform, 158(pp. 101-6.

Majumdar S, Thomasson D, Shimakawa A, Genant HK. Quantitation of the susceptibility difference between trabecular bone and bone marrow: experimental studies. Magn Reson Med 1991, 22(1): 111-27.

Majumdar S, Newitt D, Jergas M, Gies A, Chiu E, Osman D, Keltner J, Keyak J, Genant H. Evaluation of technical factors affecting the quantification of trabecular bone structure using magnetic resonance imaging. Bone 1995, 17(4):417-30.

Majumdar S, Genant HK, Grampp S, Newitt DC, Truong VH, Lin JC, Mathur A. Correlation of trabecular bone structure with age, bone mineral density, and osteoporotic status: in vivo studies in the distal radius using high resolution magnetic resonance imaging. J Bone Miner Res 1997, 12(1):111-8.

Majumdar S. Magnetic resonance imaging and spectroscopy of the intervertebral disc. NMR Biomed. 2006;19:894-904.

Manac'h YG., Gilbert G, Beaudoin G., Périé D, Sensitivity of quantitative MRI to mechanical compression of isolated intervertebral discs. Magnetic Resonance Imaging, submitted.

Mannion AF, Meier M, Grob D, Muntener M: Paraspinal muscle fibre type alterations associated with scoliosis: An old problem revisited with new evidence. Eur Spine J 1998, 7(4):289293.

McCall IW, Galvin E, O'Brien JP, Park WM. (1981), Alterations in vertebral growth following prolonged plaster immobilization. Acta Orthop Scand 52:327-30.

Meier MP, Klein MP, Krebs D, Grob D, Muntener M: Fiber transformations in multifidus muscle of young patients with idiopathic scoliosis. Spine 1997, 22(20):2357-2364.

Mente P.L., Stokes I.A., Spence H., Aronsson D.D. (1997), Progression of vertebral wedging in an asymmetrically loded rat tail model. Spine. 1997 22(12):1292-6.

Mente P.L., Aronsson D.D., Stokes I.A., Iatridis J.C. (1999), Mechanical modulation of growth for the correction of vertebral wedge deformities. J Orthop Res. 17(4):518-24.

Mwale F., Demers C.N., Michalek A.J., Beaudoin G., Goswami T., Beckman L. Iatridis J.C., Antoniou J. Evaluation of Quantitative Magnetic Resonance Imaging, Biochemical and Mechanical Properties of Trypsin-Treated Intervertebral Discs Under Physiological Compression Loading. J. Magn. Reson. Imag. 2008, 27:563-73.

Mwale F, Iatridis JC, Antoniou J. Quantitative MRI as a diagnostic tool of intervertebral disc matrix composition and integrity. Eur Spine J. 2008;17 Suppl 4:432-40.

Nguyen AM, Johannessen W, Yoder JH, Wheaton AJ, Vresilovic EJ, Borthakur A, Elliott DM. Noninvasive quantification of human nucleus pulposus pressure with use of T1rhoweighted magnetic resonance imaging. J Bone Joint Surg Am. 2008, 90(4):796-802.

Nieminen MT, Toyras J, Laasanen MS, Silvennoinen J, Helminen HJ, Jurvelin JS. Prediction of biomechanical properties of articular cartilage with quantitative magnetic resonance imaging. J Biomech 2004, 37(3):321-8.

Odermatt D, Mathieu PA, Beausejour M, Labelle H, Aubin CE. Electromyography of scoliotic patients treated with a brace. J Orthop Res 2003;21:931-6. 
Patten, C., Meyer, R. A., and Fleckenstein, J. L., 2003, "T2 Mapping of Muscle," Semin Musculoskelet Radiol, 7(4), pp. 297-305.

Périé D, Sales de Gauzy J, Curnier D, Hobatho MC. Intervertebral disc modeling using a MRI method: migration of the nucleus zone within scoliotic intervertebral discs. Magn Reson Imaging. 2001;19(9):1245-8.

Périé D., Iatridis J.C., Beaudoin G., Goswami T., Mwale F., Antoniou J. Assessment of compressive modulus and hydraulic permeability of intervertebral nucleus pulposus using quantitative MRI. Journal of Biomechanics 2006, 39(8):1392-400.

Pfirrmann CW, Metzdorf A, Zanetti M, Hodler J, Boos N. Magnetic resonance classification of lumbar intervertebral disc degeneration. Spine (Phila Pa 1976). 2001;26(17):1873-8.

Recuerda M., Gilbert G., Beaudoin G., Périé D., Quantitative MRI for the assessment of mechanical properties of intervertebral discs. BMC Musculoskeletal Disorders, submitted.

Roaf R. (1960), Vertebral growth and its mechanical control. J Bone Joint Surg [Br] 42:40-59.

Roaf R. (1963), The treatment of progressive scoliosis by unilateral growth-arrest. J Bone Joint Surg [Br] 45:637-51.

Samosky JT, Burstein D, Eric Grimson W, Howe R, Martin S, Gray ML. Spatially-localized correlation of dGEMRIC-measured GAG distribution and mechanical stiffness in the human tibial plateau. J Orthop Res. 2005, 23(1):93-101.

Schlenzka D, Poussa M, Seitsalo S, Osterman K. Intervertebral disc changes in adolescents with isthmic spondylolisthesis. J Spinal Disord. 1991;4(3):344-52.

Scoles PV, Latimer BM, DiGiovanni BF, Vargo E, Bauza S, Jellema LM. (1991), Vertebral alterations in Scheuermann's kyphosis. Spine 16:509-15.

Sirca A, Kostevc V: The fibre type composition of thoracic and lumbar paravertebral muscles in man. J Anat 1985, 141:131-137.

Stokes IA, Spence H, Aronsson DD, Kilmer N. (1996), Mechanical modulation of vertebral body growth. Implications for scoliosis progression. Spine 21(10):1162-7.

Urban MR, Fairbank JCT, Bibby SRS, Urban JPG. Intervertebral disc composition in neuromuscular scoliosis - Changes in cell density and glycosaminoglycan concentration at the curve apex. Spine. 2001;26(6):610-7.

Tsai, Y. T., Leong, C. P., Huang, Y. C., Kuo, S. H., Wang, H. C., Yeh, H. C., and Lau, Y. C., "The Electromyographic Responses of Paraspinal Muscles During Isokinetic Exercise in Adolescents with Idiopathic Scoliosis with a Cobb's Angle Less Than Fifty Degrees," Chang Gung Med J, 33(5), pp. 540-50.

Volkmann R. (1882) Verletzungen und Krankenheiten der Bewegungsorgane. In: von Pitha und Billroth: Handbuch der allgemeinen und speciellen Chirurgie Bd II Teil II. Stuttgart: Ferdinand Enke.

Wang, C., Witschey, W., Goldberg, A., Elliott, M., Borthakur, A., and Reddy, R. 2010. Magnetization transfer ratio mapping of intervertebral disc degeneration.

Weinstein SL, Ponseti IV. (1983), Curve progression in idiopathic scoliosis. J Bone Joint Surg [Am] 65:447-55.

Wehrli FW, Ford JC, Haddad JG. Osteoporosis: clinical assessment with quantitative MR imaging in diagnosis. Radiology 1995, 196(3):631-41. 
Wheaton AJ, Dodge GR, Elliott DM, Nicoll SB, Reddy R. Quantification of cartilage biomechanical and biochemical properties via T1rho magnetic resonance imaging. Magn Reson Med. 2005, 54(5):1087-93.

Wright, P., Mougin, O., Totman, J., Peters, A., Brookes, M., Coxon, R., Morris, P., Clemence, M., Francis, S., Bowtell, R., et al. 2008. Water proton measurements in brain tissue at 7, 3, and 1.5T using IR-EPI, IR-TSE, and MPRAGE: results and optimization. Magnetic Resonance Materials in Physics, Biology and Medicine 21:121-130.

Zetterberg C, Aniansson A, Grimby G: Morphology of the paravertebral muscles in adolescent idiopathic scoliosis. Spine 1983, 8(5):457-462.

Zuo J, Joseph GB, Li X, Link TM, Hu SS, Berven SH, Kurhanewitz J, Majumdar S. In-vivo Intervertebral Disc Characterization using Magnetic Resonance Spectroscopy and T1 $\rho$ Imaging: Association with Discography and Oswestry Disability Index and SF36. Spine 2011 [Epub ahead of print]. 


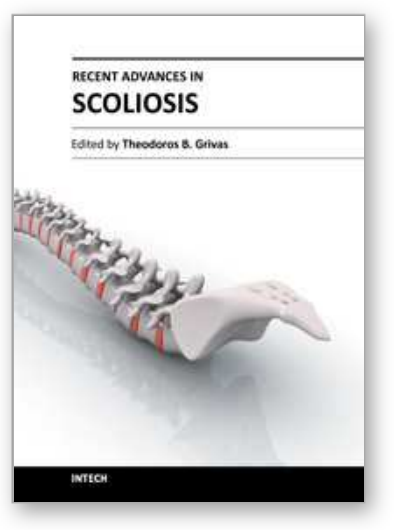

\author{
Recent Advances in Scoliosis \\ Edited by Dr Theodoros Grivas
}

ISBN 978-953-51-0595-4

Hard cover, 344 pages

Publisher InTech

Published online 09, May, 2012

Published in print edition May, 2012

This book contains information on recent advances in aetiology and pathogenesis of idiopathic scoliosis, for the assessment of this condition before treatment and during the follow-up, making a note of emerging technology and analytical techniques like virtual anatomy by 3-D MRI/CT, quantitative MRI and Moire Topography. Some new trends in conservative treatment and the long term outcome and complications of surgical treatment are described. Issues like health related quality of life, psychological aspects of scoliosis treatment and the very important "patient's perspective" are also discussed. Finally two chapters tapping the untreated early onset scoliosis and the congenital kyphoscoliosis due to hemivertebra are included. It must be emphasized that knowledgeable authors with their contributions share their experience and enthusiasm with peers interested in scoliosis.

\title{
How to reference
}

In order to correctly reference this scholarly work, feel free to copy and paste the following:

Périé Delphine (2012). Quantitative MRI for Scoliosis Follow-Up, Recent Advances in Scoliosis, Dr Theodoros Grivas (Ed.), ISBN: 978-953-51-0595-4, InTech, Available from: http://www.intechopen.com/books/recentadvances-in-scoliosis/quantitative-mri-for-scoliosis-follow-up

\section{INTECH}

open science | open minds

\section{InTech Europe}

University Campus STeP Ri

Slavka Krautzeka 83/A

51000 Rijeka, Croatia

Phone: +385 (51) 770447

Fax: +385 (51) 686166

www.intechopen.com

\section{InTech China}

Unit 405, Office Block, Hotel Equatorial Shanghai

No.65, Yan An Road (West), Shanghai, 200040, China

中国上海市延安西路65号上海国际贵都大饭店办公楼405单元

Phone: +86-21-62489820

Fax: $+86-21-62489821$ 
(C) 2012 The Author(s). Licensee IntechOpen. This is an open access article distributed under the terms of the Creative Commons Attribution 3.0 License, which permits unrestricted use, distribution, and reproduction in any medium, provided the original work is properly cited. 